\title{
Rainbow of Natural Dyes on Textiles Using Plants Extracts: Sustainable and Eco-Friendly Processes
}

\author{
Jyoti Arora*, Prerna Agarwal, Gunjan Gupta \\ Department of Zoology, Miranda House, University of Delhi, Delhi, India \\ Email: ${ }^{\star}$ jyotiarora75@hotmail.com, *jyoti.arora@mirandahouse.ac.in
}

How to cite this paper: Arora, J., Agarwal, P. and Gupta, G. (2017) Rainbow of Natural Dyes on Textiles Using Plants Extracts: Sustainable and Eco-Friendly Processes. Green and Sustainable Chemistry, 7, 35-47. https://doi.org/10.4236/gsc.2017.71003

Received: September 19, 2016

Accepted: February 21, 2017

Published: February 24, 2017

Copyright (๑) 2017 by author(s) and Scientific Research Publishing Inc. This work is licensed under the Creative Commons Attribution-NonCommercial International License (CC BY-NC 4.0). http://creativecommons.org/licenses/by-nc/4.0/ (c) (7) \&) Open Access

\begin{abstract}
Indians have been considered as forerunners in the art of natural dyeing. Although indigenous knowledge system has been practiced over the years in the past, the use of natural dyes has diminished over generations due to lack of documentation and precise knowledge of the extracting and dyeing techniques. As a result, natural dyes are not commercially successful. Presently, all environmentally unfriendly synthetic compounds are used for dyeing textile materials. They are non-biodegradable, carcinogenic and generate water pollution as well as waste disposal problems. Natural dyes provide a reasonable solution to these problems. Thus, it is imperative to develop technology for extraction of natural dyes and for their application on textile materials. In this study, attempt has been made to extract natural dyes from a variety of plants sources (such as rhizomes of turmeric, Curcuma longa; fruits of harda, Terminalia chebula; petals of safflower, Carthamus tinctorius, roots of barberry, Berberis lycium etc.) using specific techniques. These dyes were tested for their dyeing potential on different textile materials (cotton, silk and wool). Dyeing was done using three different dyeing techniques (pre-, simultaneous- and post-mordanting) wherein different mordants such as alum, copper sulphate and ferrous sulphate etc., were used to fix dye on to the textile material. A rainbow of natural dyes was obtained with varied shades of each colour. Shade cards were prepared for each dye and the colour obtained varied depending on the type of the mordant applied and the mordanting technique used.
\end{abstract}

\section{Keywords}

Natural Dyes, Rainbow, Textiles, Eco-Friendly, Sustainable

\section{Introduction}

Natural dyes have been used as colourants in food, leather as well as textile since 
prehistoric times. These dyes are obtained from vegetable and animal matter with no or very little chemical processing. In 1856, cheaper and easily available synthetic dyes were introduced, which resulted in a drastic decline in the usage of natural dyes. However, there has been a revival of interest in natural dyes in the global arena due to their non-polluting, non-carcinogenic and eco-friendly nature [1] [2]. Environmentalists are always worried about the rampant use of synthetic dyes in textile industry as they cause water pollution and waste disposal problems [3]. Natural dyes are biodegradable and do not cause any health hazards and hence they can be easily used without much environment concerns. Despite this, use of natural dyes for dyeing textiles has been restricted mainly to artisan/craftsman, small scale/cottage level dyers and printers as well as to small scale exporters and producers dealing with high-valued eco-friendly textile production and sales [4]. Recently, many commercial dyers have started using natural dyes to overcome the environmental damage caused by synthetic dyes. Also, synthetic dyes such as azo dyes are reported to be carcinogenic and can cause allergic reactions [4]. Germany was the first to take initiative to put ban on production and use of numerous specific azo dyes. Netherlands, India and some other countries also followed the ban [5].

Natural dyes are well known for producing very uncommon, soothing and soft shades as compared to synthetic dyes. This shift in paradigm in favour of natural dyes is also attributed to the stringent environmental standards imposed by many countries in response to toxic and allergic reactions associated with synthetic dyes [6]. Natural dyes exhibit several important properties that provide them a significant edge over synthetic dyes. Some of these advantages are as follows:

- being biodegradable, non-toxic and non-allergic;

- being environment friendly and aesthetically appealing;

- employment generation and utilization of wasteland;

- easy extraction of colors by boiling the plants, berries, leaves, bark or flower heads in water;

- synthetic dyes such as azo dyes are carcinogenic and can produce toxic and allergic reactions;

- fabric dyed with natural dyes exhibits higher UV absorption that can result in reduced incidence of melanoma;

- many natural dyes have antibacterial properties;

- natural dyes are mostly renewable as most of them are plant based whereas synthetic dyes are petroleum-based that is a non-renewable source of energy. Thus, application of natural dyes instead of fossil fuel (petroleum) based synthetic dyes has the potential of earning carbon credits;

- the waste generated can be used as bio-fertilizers in some cases such as dyeing with indigo, and as a result there is no waste disposal problem;

- a wide spectrum of colours by mix and match system can be produced;

- a small variation in the mordant used or extraction medium or dyeing technique can bring about a drastic change in the colour; 
- natural dyes bleed but do not stain other fabrics except turmeric;

- natural dyes are moth proof and can replace synthetic dyes in kids garment and food stuff for safety.

However, there are several limitations of natural dyes also some of which are listed below:

- lack of availability of precise knowledge of extraction and dyeing technique;

- reproducibility of the same shade is difficult;

- mordant is required to fix the dye into the fabric;

- skilled man power is required;

- expensive and colour and light fastness is low.

Despite several limitations, there has been a trend to revive the art of natural dyeing in recent years. This is largely due to increase in environment consciousness among the general masses worldwide.

India has a rich biodiversity and there are more than 450 plants yielding dyes and pigments [7]. However, many of these plant dyes are not yet fully explored for their potential in dyeing textiles. In addition, there is an urgent need to devise a suitable, scientific technique for extraction of dyes and their application on textile materials without compromising the quality of the fabric. Majority of the plants used for extraction of dyes are classified as medicinal and some of these have recently been shown to exhibit antimicrobial effect [7] [8]. The antibacterial activity of some of these dyes is due to the presence of phenol, tannin and quinine in their extracts. When these dyes were applied to textiles, the antimicrobial properties of these plant dyes contribute to the longer life of the textile materials [9].

In this study, the dyeing potential of different natural dyes extracted from varied plants was evaluated on different textile materials. The major objectives were as follows: 1) Extraction of dyes from different plant materials available locally or collected from the regional flora; 2) Application of natural dyes to various textile materials; 3) Study the effect of different types of mordants and mordanting techniques in the dyeing process; 4) To obtain different colours of rainbow on textile using plant dyes and simple, effective, eco-friendly and sustainable methods.

\section{Materials and Methods}

\subsection{Materials}

\subsubsection{Textile Materials}

Three textiles made of natural fibers viz., cotton (plant origin) and silk as well as wool (animal origin) were chosen for this study.

\subsubsection{Plant Materials}

A variety of plant sources were explored for their dyeing potential (Table 1).

\subsubsection{Mordants}

Three mordants viz., Aluminium Potassium Sulphate, Ferrous Sulphate, Copper Sulphate were tested for this study. 
Table 1. List of plants used for extraction of natural dyes along with the dyeing techniques.

\begin{tabular}{|c|c|c|c|c|c|c|}
\hline Shade & Plant & Plant part & Extract & Mordant & Technique & Formic Acid \\
\hline \multirow{2}{*}{ Red } & Red Sandalwood & Bark & Acidic & Alum & Simultaneous & + \\
\hline & Red Sandalwood & Bark & Basic & Alum & Simultaneous & + \\
\hline \multirow{3}{*}{ Orange } & Madder & Roots & Neutral & Alum & Simultaneous & + \\
\hline & Madder & Roots & Alcoholic & Alum & Simultaneous & + \\
\hline & Red Sandalwood & Bark & Neutral & Alum & Simultaneous & + \\
\hline \multirow{6}{*}{ Yellow } & Safflower & Dried Petals & Alcoholic & Alum & Simultaneous & + \\
\hline & Safflower & Dried Petals & Neutral & Alum & Simultaneous & + \\
\hline & Turmeric & Rhizome & Neutral & Alum & Simultaneous & + \\
\hline & Harda & Fruits & Neutral & Alum & Simultaneous & + \\
\hline & Berberis & Roots & Neutral & Alum & Simultaneous & + \\
\hline & Mulberry & Leaves & & & Simultaneous & - \\
\hline Blue & Indigo $^{*}$ & Leaves & & & & \\
\hline \multirow{2}{*}{ Green } & Indigo $^{\star}+$ Berberis & Leaves Roots & & & & \\
\hline & Indigo ${ }^{\star}+$ Peppermint & Leaves & & & & \\
\hline \multirow{3}{*}{ Violet } & Red Sandalwood & Bark & Acidic & Ferrous Sulphate & Simultaneous & + \\
\hline & Alkanet & Roots & Alcoholic & Alum & Simultaneous & + \\
\hline & Jamun & Fruit Pulp & Neutral & Alum & Simultaneous & + \\
\hline \multirow{6}{*}{ Brown-green } & Basil & Leaves & Neutral & Alum & Simultaneous & + \\
\hline & Onion peel & Dried Peels & Neutral & Alum & Simultaneous & - \\
\hline & Spinach (unboiled) & Leaves & Neutral & Alum & Simultaneous & + \\
\hline & Heena & Leaves & Neutral & Alum & Simultaneous & + \\
\hline & Hibiscus & Petals & Basic & Alum & Simultaneous & + \\
\hline & Hibiscus & Petals & Acidic & Alum & Simultaneous & + \\
\hline
\end{tabular}

${ }^{\star}$ For Indigo, different method was used (refer 2.2.6).

\subsection{Methods}

\subsubsection{Extraction of Dyes from Plant Materials}

Dye extract (3\%) was prepared by dissolving $15 \mathrm{gm}$ of dye powder or crushed flower material in $500 \mathrm{ml}$ of distilled water. The solution was then kept for boiling on a hot plate for 30 minutes and after boiling the final volume was adjusted to $500 \mathrm{ml}$ with water. Extraction was done in three different mediums (acidic = $\mathrm{pH}$ 2; Basic = pH 8; Neutral = pH 7).

\subsubsection{Dyeing Techniques}

The dyeing recipe followed is given in Table 2. Three different mordanting techniques were used viz., Premordanting, Simultaneous mordanting and Postmordanting. 
Table 2. Dyeing recipe followed for the different textile materials.

\begin{tabular}{cc}
\hline Parameters & Dyeing Recipe \\
\hline Material to liquor & $1: 30$ \\
Dye extract (C) & $3 \%$ \\
Formic acid & $0.5 \mathrm{ml}$ \\
$\mathrm{pH}$ & 4 \\
Time & $60 \mathrm{~min}$ \\
Temperature & $85^{\circ} \mathrm{C}$ \\
\% of dye solution to be made $(\mathrm{P})$ Dye $(\mathrm{ml})=\left(\mathrm{W}^{*} \mathrm{P}\right) / \mathrm{C}$ & $30 \%$ \\
\hline (W-weight of cloth; $\mathrm{P}-\%$ of dye solution to be made; $\mathrm{C}-\%$ of dye extract $)$ &
\end{tabular}

\subsubsection{Premordanting}

The pre-soaked material was dipped in required mordanting solution for 20 - 30 $\min$ at $80^{\circ} \mathrm{C}$. Dyeing was done with natural dye at $85^{\circ} \mathrm{C}$ for $40-60 \mathrm{~min}$. The material was cold washed and then washed with $1 \%$ mild detergent for $5-10$ min. Finally, the material was cold washed and dried under shade.

\subsubsection{Simultaneous Mordanting}

The pre-soaked material was put in the dyeing bath. On the weight of material required volume of dye solution, mordant and water was added in the dye bath. At $40^{\circ} \mathrm{C}$, the material was put in the dye bath and $2-3$ drops of formic acid was added. Temperature was raised to $85^{\circ} \mathrm{C}$ and dyeing was done for $60 \mathrm{~min}$. The material was cold washed followed by soaping, washing and drying.

\subsubsection{Postmordanting}

The material was dyed in natural dye at $85^{\circ} \mathrm{C}$ for $40-60 \mathrm{~min}$ and cold washed. The material was put in mordanting solution for $20-30 \mathrm{~min}$ at $80^{\circ} \mathrm{C}$ temperature. The material was dried under shade without washing. Soaping with $1 \%$ mild detergent was done for $5-10 \mathrm{~min}$ and cold washed and then dried under shade.

\subsubsection{Dyeing with Indigo}

Indigo cakes were brought from the market and were crushed to form powder. A paste was made by dissolving $15 \mathrm{~g}$ of the indigo powder in a small amount of warm water. Hot water $\left(50^{\circ} \mathrm{C}\right)$ was added to the paste and then a few fructose crystals and $1 \mathrm{~g}$ of calcium hydroxide was added. The solution was stirred constantly to prevent formation of lumps. The entry of air to the solution was prevented to avoid oxidation of indigo. Again hot water was added on top of the solution and subsequently a greenish murky solution was formed. The solution was left for an hour to settle. After an hour, the solution separated out into two layers. The solution was stirred in an interval of 15 to $20 \mathrm{~min}$ for about 3 or 4 times. The processed solution was then used for dyeing textiles. The fabric was dipped in the solution and fabric was dipped several times to increase the intensity of the shade. Finally, the fabric was dried in air and oxidation of the dye gave a blue colour to the fabric. Less number of dip gave blue color whereas more number of the dips imparted indigo color to the fabric. Fabric was air dried for a 
while after each dip and after the last dip a cold wash was given and the cloth was dried.

\section{Results and Discussion}

\subsection{Rainbow of Natural Dyes}

A variety of natural dyes are obtained from different plants parts viz., roots, bark, leaf, fruit, bark, seed, flower etc., that produce varied colours such as red, yellow, blue etc. [1]. Of the total 2000 plant pigments known so far worldwide, only 150 have been commercially exploited. In Indian context, 50 of the total 450 dye yielding plants are considered to be very important [1]. On the basis of colours, natural dyes can be classified as Red dyes, yellow dyes, blue dyes and black dyes. Red colour dyes (e.g. Madder) are mostly extracted from roots or barks of plants and are usually based on anthraquinone and its derivatives (Figure 1). These dyes are stable to light and washing.

Yellow colour dyes are the most common colour found in nature and majority (ca. 90\%) are flavonoids. They are known to produce pale shades, less light fastness and fairly good wash fastness e.g., tesu, turmeric, kapila (Figure 2). Blue

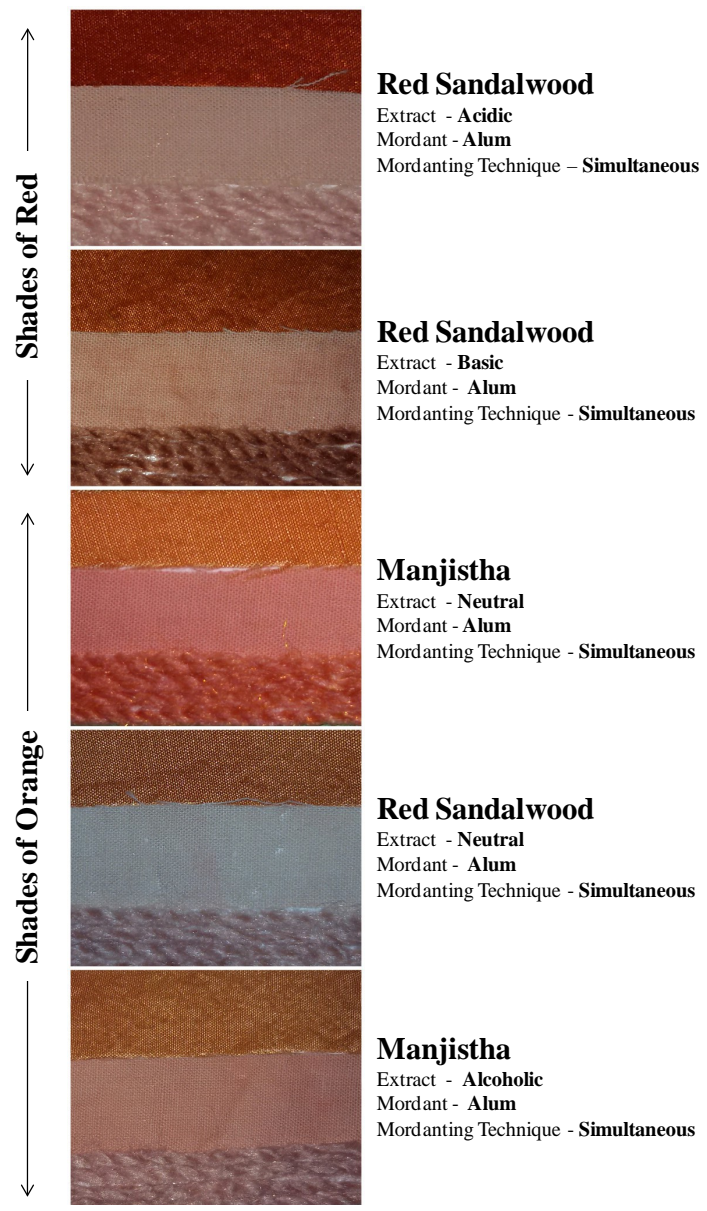

Figure 1. Shades of orange and red produced by natural dyes on silk (top), cotton (middle) and wool (bottom) in each card. Extract type, mordant and mordanting technique used is indicated. 


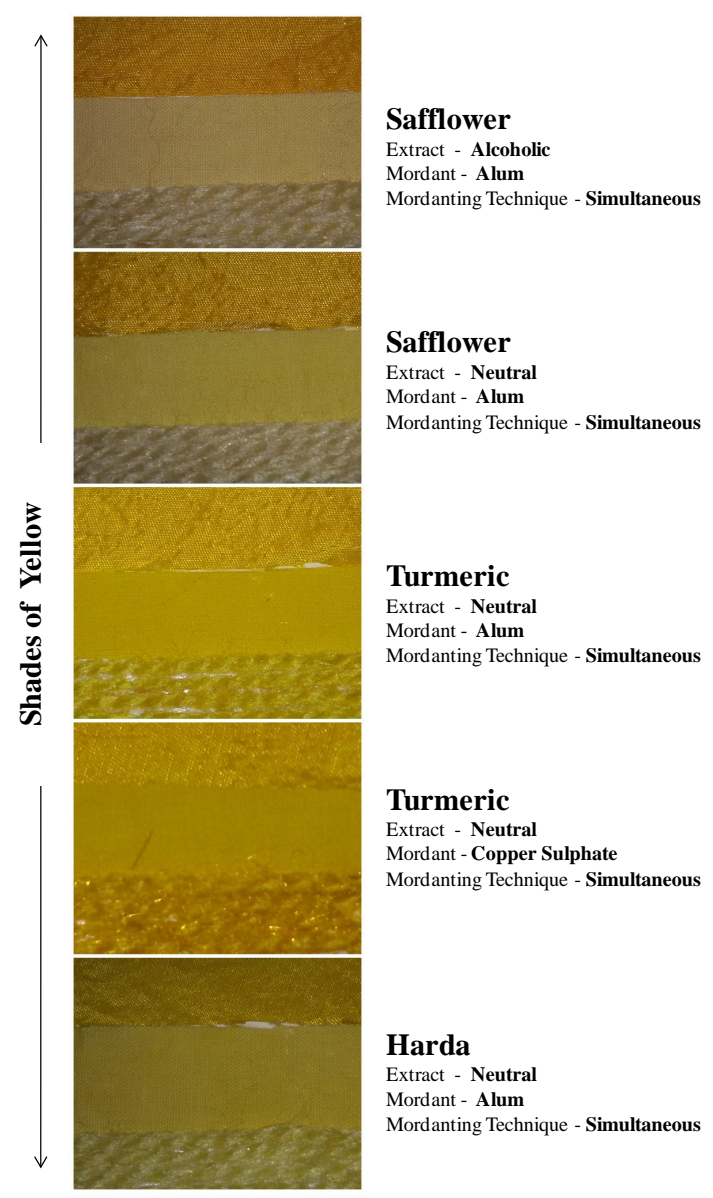

Figure 2. Shades of yellow produced by natural dyes on silk (top), cotton (middle) and wool (bottom) in each card. Extract type, mordant and mordanting technique used is indicated.

colour dyes (e.g., indigo) gives excellent fastness to light and washing (Figure 3). Black shades are usually derived from tannin rich plant dyes and are fairly substantive towards cellulosic and protein fibre with good overall fastness properties, for example, Logwood, Harda etc. In this study, a variety of natural dyes were evaluated for obtaining a spectrum of colours such as red colour from red sandel wood; Orange from Madder; Yellow from Safflower, Turmeric, Berberris and Harda; Blue from Indigo; Green from a combination of Indigo and Berberris; Violet from Alkanet; Brown-green from Basil, Eucalyptus, Heena and Hibiscus (Table 1; Figures 1-7).

\subsection{Extraction of Natural Dyes}

The efficiency of extraction of coloured components present in plants depends on medium of extraction (aqueous or solvent or acids/alkali), $\mathrm{pH}$ of the Medium (acidic/alkali/neutral) and conditions of extraction (temperature, time, materialto-liquor ratio and particle size of the substrate). Optimum conditions of extraction variables are determined through extracting the natural colour component from source material by varying extraction parameters of liquor and measuring the optical density of corresponding coloured liquor by using spectrophotometer. 


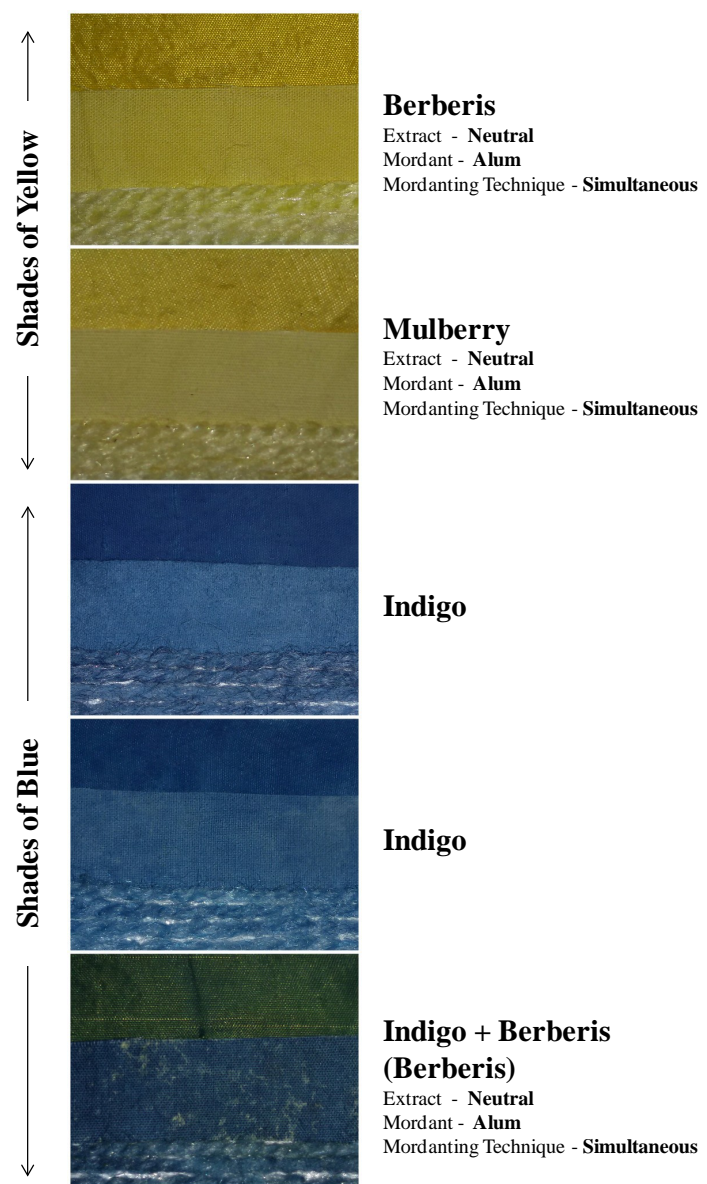

Figure 3. Shades of yellow and blue produced by natural dyes on silk (top), cotton (middle) and wool (bottom) in each card. Extract type, mordant and mordanting technique used is indicated. For indigo, different method was used as given in 2.2.6.

Also, the gravimetric yield of colour can be measured by filtering the extraction liquor through standard filtration process followed by evaporation of solvent, washing and finally drying to get the purified natural colour. In addition, it is important to note that the amount of dye present in plant varies greatly depending on the season, age of the plants, and some other factors. Natural dyes extracted in three different $\mathrm{pH}$ mediums (acidic, neutral and alkaline) have been tested for their dyeing potential using different mordanting techniques and three different mordants. It was observed that for most of the plant dyes extraction was better with alkaline medium.

\subsection{Application of Mordants and Process of Dyeing}

A dye comprises of two principal groups: the chromophore and auxochromes. Chromophore (usually an aromatic ring) is associated with the colouring property and has unsaturated bonds, whose numbers decides the intensity of colour. The auxochrome helps the dye molecule to combine with the substrate, thus imparting colour to the latter. Although some fabrics such as silk and wool can be colored simply by dipping in the dye, others such as cotton require a mordant. Some natural dyes, such as indigo will give good color when used alone; 


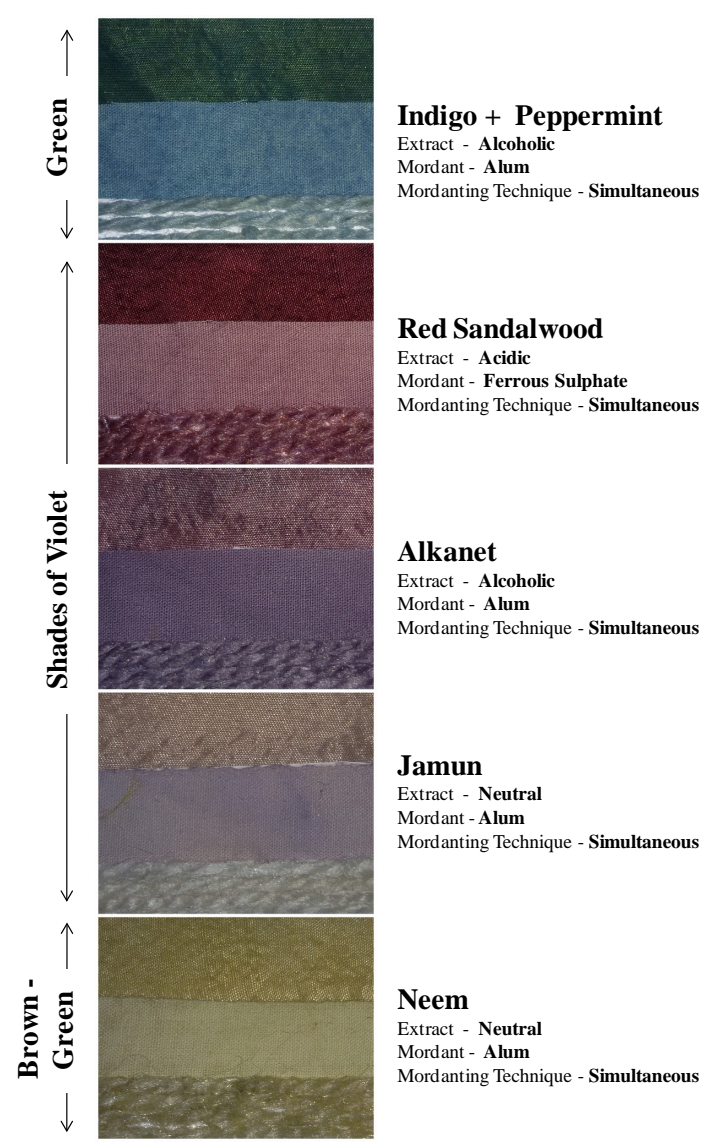

Figure 4. Shades of green, violet and brown-green produced by natural dyes on silk (top), cotton (middle) and wool (bottom) in each card. Extract type, mordant and mordanting technique used is indicated.

these dyes are called direct dyes or substantive dyes. The majority of plant dyes, however, require a mordant or a chemical used to "fix" the color to the textile fabric, and prevent the color from either fading with exposure to light or washing out. These dyes are called adjective dyes such as logwood. By using different mordants, dyers can often obtain a variety of colors and shades from the same dye. Fibers or cloth may be pre-treated with mordants, or the mordant may be incorporated in the dye bath. Mordants can be broadly classified into three types: Metallic mordants (Metal salts of iron, copper aluminium etc.); Tannins (Myrobalan and Sumach); Oil Mordants (mainly used in dyeing Turkey red colour from Madder). The final colour, lustre and colour fastness properties of the dyed fabric are dependant not only on the dye but are also determined by the concentration and type of mordants used. Thus, a mordant is more important than the dye itself. Thus, an ideal mordant will be the one that produce required colour yield at low cost without affecting the physical properties of fabric. It should not cause any noxious effect during processing and the dyed textile material should not have any carcinogenic effect during use. Common mordants are alum (usually used with cream of tartar, which helps evenness and brightens slightly); iron (or copper) (which saddens or darken colors, bringing out green shades); tin (usually used with cream of tartar, which blooms or brightens colors, 


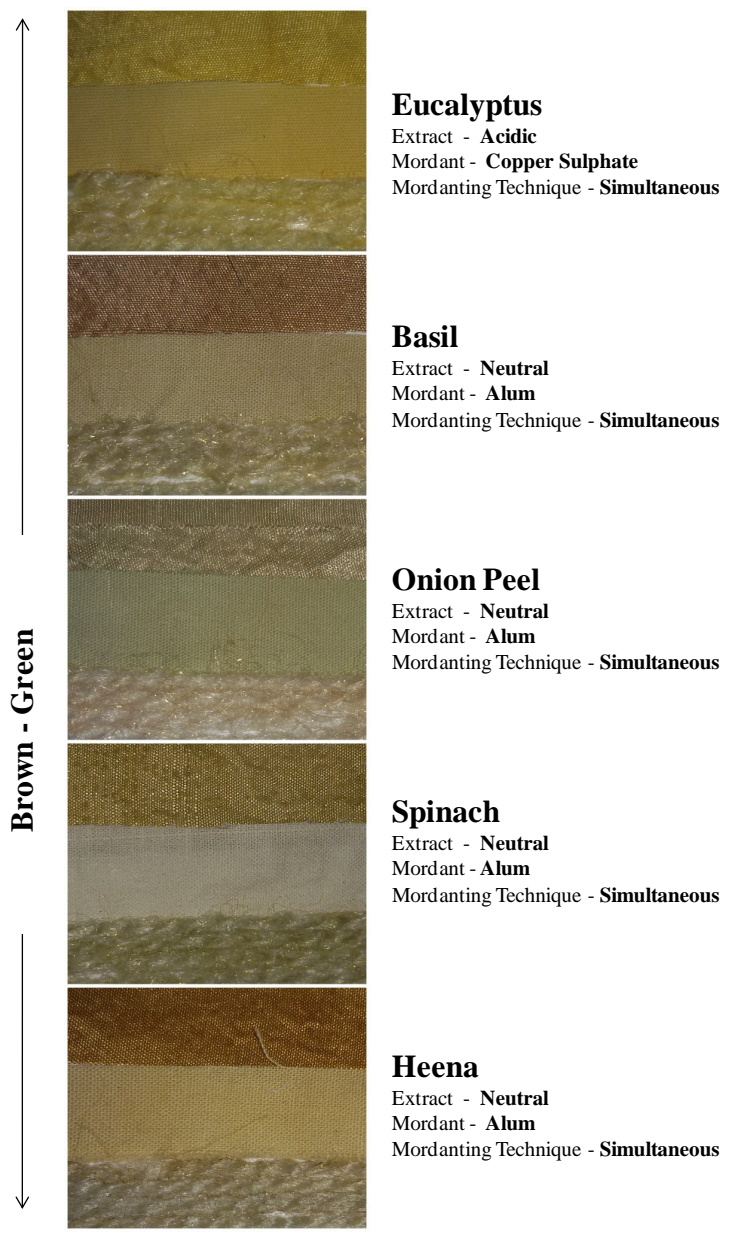

Figure 5. Shades of brown-green produced by natural dyes on silk (top), cotton (middle) and wool (bottom) in each card. Extract type, mordant and mordanting technique used is indicated.

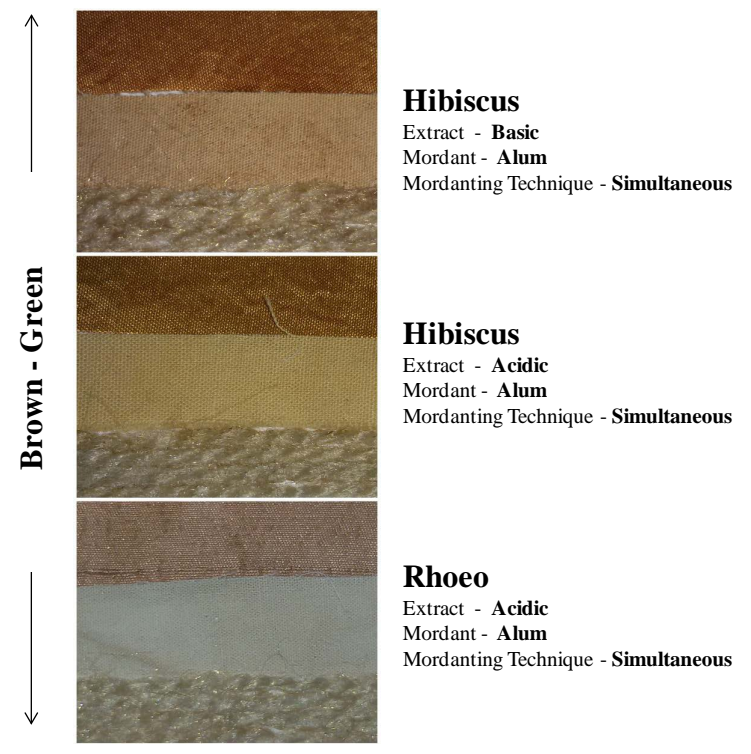

Figure 6. Shades of brown-green produced by natural dyes on silk (top), cotton (middle) and wool (bottom) in each card. Extract type, mordant and mordanting technique used is indicated. 


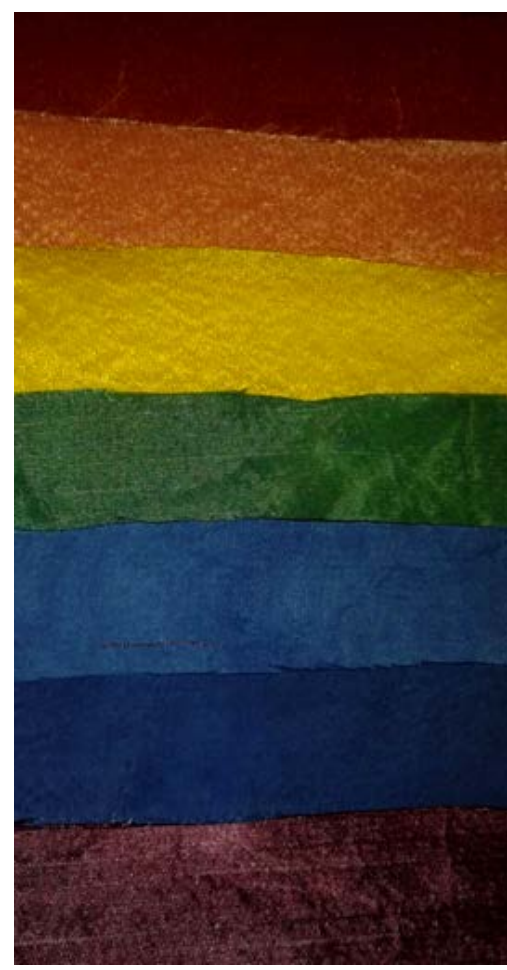

RED $=$ RED SANDALWOOD

Acidic Extract; Simultaneous Mordanting; Alum

\section{ORANGE $=$ MANJISTHA}

NeutralExtract; Simultaneous Mordanting; Alum

YELLOW = TURMERIC

Neutral Extract; Simultaneous Mordanting; Alum

GREEN = INDIGO + BERBERIS

(Berberis - Neutral Extract; Simultaneous

Mordanting; Alum)

BLUE = INDIGO

INDIGO $=$ INDIGO

VIOLET $=$ RED SANDALWOOD

Acidic Extract; Simultaneous Mordanting; Ferrous Sulphate

Figure 7. Rainbow of natural dyes on silk. Natural dye, extract type, mordant and mordanting technique used is indicated. For Indigo, different method was used as given in 2.2.6.

especially reds, oranges and yellows), and blue vitriol (which saddens colors and brings out greens shades). In present study, it was observed that alum does not alter the colour of original dye; Copper sulphate elevates the colour and gives greenish hue to the fabric and ferrous sulphate adds blackish hue to the colour and gives the shades of grey and black making colour dark and dull.

Different types of mordant and method of mordanting significantly affect the rate and extent of photo fading. For example, Copper or ferrous sulphate gives high resistance to fading, whereas stannous chloride does not. In comparison, light fastness improves when post-mordanting is conducted with copper or ferrous ion but pre-mordanting is superior in case of stannous chloride or alum [10]. Synergistic effect of mordant is generally observed while using binary combinations of mordants. It has been reported that the combinations of harda and aluminium sulphate as double mordants are best suited for jute fabric for red sandal wood natural dye [11]. Various kinds of shades like black to brown and green to yellow to orange can be obtained by application of varied mordants [4]. Mordants form metal complexes between fabric and dye. On application of mordant, the metal salts anchoring to the fibres, attracts the dye/organic pigment molecules to be anchored to the fibres and finally creates the bridging link between the dye molecules and the fibre by forming coordinating complexes.

$\mathrm{pH}$ of the dyeing bath can be alkaline, acidic or neutral. There are various reports available on different methods of mordanting on different fibers such as cellulosic, protenic and synthetic for dyeing with different natural dyes. Dyeing 
of cotton and silk with babool, tesu, manjistha, heena, indigo, marigold etc is reported [12] [13] [14] [15]. Depending upon the fabric to be dyed, the different parameters of the dyeing bath are modified to get the desired results. Besides the conventional method of dyeing in a dye bath at a specific temperature in the presence of suitable mordants, newer technologies have also been tested these days. These technologies include use of nanoparticles, ultrasonics energized dyeing, use of supercritical carbon dioxide $\left(\mathrm{scCO}_{2}\right)$ as a fluid medium [4].

The resistance of a material to change its colour or extent of transfer of its colours to adjacent white materials in touch is referred to as colour fastness. For any textile, it is measured with respect to degree of loss of colour or in terms of a staining scale i.e. the extent to which the colour is passed on to the accompanying white material. Generally, light fastness, wash fastness and rub fastness are measured for testing the efficacy of dyeing of textiles. Light fastness of most natural dyes particularly those derived from flower petals are found to be poor-medium. Yellow dyes showed poor light fastness; reds showed better light fastness followed by blue and black. However, the use of mordants has shown to improve the fastness properties. The $\mathrm{pH}$ of washing medium plays a very important role in improving the wash fastness of textiles dyed with natural dyes. Generally, natural dyes show moderate wash fastness. Logwood and indigo dyes showed better wash fastness. Majority of natural dyes exhibited moderate to good rub fastness and does not require any after-treatment.

\section{Conclusion}

The intensity of color of dye extracted from the same plant material changes with the $\mathrm{pH}$ of the medium. Color of the dye on the fabric was the function not only of the mordant but also of the dyeing technique. From the same plant extract but with different mordants and dyeing techniques, different colors were obtained (Figures 1-7). Blending of the colors can also be done. Best colors were obtained on the silk fabric followed by the wool and lastly cotton. Using different plant dyes the entire rainbow of colours could be created (Figure 7). Modern techniques of extraction are a better approach which is cost- and time-efficient and a good yield of dye can be obtained.

\section{Acknowledgements}

We thank Dr. Pratibha Jolly, Principal, Miranda House and PI, DSKC for providing the necessary research facilities and for her constant support and encouragement.

\section{References}

[1] Siva, R. (2007) Status of Natural Dyes and Dye-Yielding Plants in India. Current Science, 92, 916-925.

[2] Ali, N.F., EL-Mohamedy, R.S.R. and El-Khatibl, E.M. (2011) Antimicrobial Activity of Wool Fabric Dyed with Natural Dyes. Research Journal of Textile and Appeal, 15, 1-10. https://doi.org/10.1108/RJTA-15-03-2011-B001 
[3] Ali, N.F., El-Mohamedy, R.S.R. and Rajput, S. (2013) Improvement of Antimicrobial Activity for Onion Natural Dyed Fabrics through Chitosan Pretreatment. Journal of Applied Sciences Research, 9, 4993-5002.

[4] Samanta, A.K. and Agarwal, P. (2009) Application of Natural Dyes on Textiles. Indian Journal of Fibre and Textile Research, 34, 384-399.

[5] Patel, N.K. (2011) Natural Dye Based Sindoor. Life Sciences Leaflets, 11, 355-361.

[6] Grover, N. and Patni, V. (2011) Extraction and Application of Natural Dye Preparations from the Floral Parts of Woodfordia fruticosa (Linn.) Kurz. Indian Journal of Natural Products and Resources, 2, 403-408.

[7] Mahesh, S., Reddy, A.H.M. and Vijaya Kumar, G. (2011) Studies on Antimicrobial Textile Finish Using Certain Plant Natrual Products. International Conference on Advances in Biotechnology and Pharmaceutical Sciences (ICABPS 2011), Bangkok, 23-24 December 2011, 253-258.

[8] Chengaiah, B., Rao, K.M., Kumar, K.M., Aagusundaram, M. and Chetty, C.M. (2010) Medicinal Importance of Natural Dyes-A Review. International Journal of PharmTech Research, 2, 144-154.

[9] Calis, A., Celik, G.Y. and Katircioglu, H. (2009) Antimicrobial Effect of Natural Dyes on Some Pathogenic Bacteria. African Journal of Biotechnology, 8, 291-293.

[10] Gupta, D., Kumar, S. and Laha, A. (2004) Antimicrobial Properties of Natural Dyes against Gram-Negative Bacteria. Colouration Technology, 120, 167-171. https://doi.org/10.1111/j.1478-4408.2004.tb00224.x

[11] Samanta, A.K. and Konar, A. (2011) Dyeing of Textiles with Natural Dyes. In: Akcakoca Kumbasar, E., Ed., Natural Dyes, InTech, Fontana, CA.

http://www.intechopen.com/books/natural-dyes/dyeing-of-textiles-with-natural-dyes

[12] Gulrajani, M.L. and Gupta, D. (1992) Natural Dyes and Application to Textiles. Department of Textile Technology, Indian Institute of Technology, New Delhi, India.

[13] Saxena, S., Varadarajan, P.V. and Nachane, N.D. (2001) Proceeding of Convention of Natural Dyes. Gupta, D. and Gulrajani, M.L., Eds., Department of Textile Technology, IIT, Delhi, 185.

[14] Vankar, P.S., Tiwari, V. and Ghorpade, B. (2001) Proceeding of Convention of Natural Dyes. Gupta, D. and Gulrajani, M.L., Eds., Department of Textile Technology, IIT Delhi, 5.

[15] Patel, R. and Agarwal, B.J. (2001) Proceeding of Convention of Natural Dyes. Gupta, D. and Gulrajani, M.L., Eds., Department of Textile Technology, IIT Delhi, 167. 
Submit or recommend next manuscript to SCIRP and we will provide best service for you:

Accepting pre-submission inquiries through Email, Facebook, LinkedIn, Twitter, etc. A wide selection of journals (inclusive of 9 subjects, more than 200 journals)

Providing 24-hour high-quality service

User-friendly online submission system

Fair and swift peer-review system

Efficient typesetting and proofreading procedure

Display of the result of downloads and visits, as well as the number of cited articles Maximum dissemination of your research work

Submit your manuscript at: http://papersubmission.scirp.org/

Or contact gsc@scirp.org 